\title{
POLÍTICA DA RESERVA DE DESENVOLVIMENTO SUSTENTÁVEL (RDS) DO TUPÉ, NO AMAZONAS, E AS EDUCAÇÕES NO CONTEXTO AMAZÔNICO
}

\author{
POLÍTICA DE RESERVA DE DESARROLLO SOSTENIBLE (RDS) DE TUPÉ EN \\ AMAZONAS Y LA EDUCACIÓN EN EL CONTEXTO AMAZÓNICO
}

\author{
TUPÉ SUSTAINABLE DEVELOPMENT RESERVE (RDS) POLICY IN AMAZONAS \\ AND EDUCATIONS IN THE AMAZON CONTEXT
}

\author{
Heloísa da Silva BORGES ${ }^{1}$ \\ Carlos Augusto da SILVA ${ }^{2}$ \\ Riulma Ventura MULLER ${ }^{3}$
}

RESUMO: O artigo apresenta uma parte da pesquisa realizada no Curso de Mestrado do Programa de Pós-Graduação em Educação da UFAM, no período de 2017 a 2019, intitulada Políticas Públicas e Educação do Campo no Contexto Amazônico: Estudo na RDS do Tupé, na Comunidade de São João - Manaus/AM. Por ser fruto dessa pesquisa, este artigo recebeu o título Politica da Reserva de Desenvolvimento Sustentável (RDS) do Tupé, no Amazonas, e as Educações no Contexto Amazônico, uma vez que faz referência a um dos objetivos específicos do estudo, que é examinar os documentos de criação dessa RDS e suas políticas públicas para educação. Os procedimentos metodológicos se basearam em estudos bibliográficos de vários autores: Brandão (2013), Caldart (2015), Freire (2003), Gohn (2020), Silva (2017), Muller (2019), Pinto (2010), Borges (2015). Também foram analisados os seguintes documentos: Constituição Federal de 1988; LDB n. ${ }^{\circ}$ 9.394/96; Lei n. ${ }^{\circ} 3.173$, de 6 de junho de 1957; Decreto-Lei n. ${ }^{\circ}$ 288, de 1967; Decreto 8.044/2005, de criação da RDS/SEMMA (04/11/2020); Plano de Gestão (2016). Ao longo do estudo foi possível constar que, nessa RDS, existem três educações: a não formal, a formal e a informal. Os dados obtidos revelam que, apesar da conquista de legislações que tratam das políticas públicas que atendam às comunidades ribeirinhas, no que se refere à educação formal, sobretudo à Educação Básica, a Comunidade de São João do Tupé ainda é atendida apenas por políticas paliativas.

PALAVRAS-CHAVE: Contexto amazônico. Políticas pública. Educação não formal. Educação formal. Educação informal.

RESUMEN: El artículo presenta parte de la investigación realizada en la Maestría del Programa de Posgrado en Educación de la UFAM, de 2017 a 2019, titulada Políticas Públicas y Educación Rural en el Contexto Amazónico: Estudio en la Reserva Tupé, en la Comunidad de São João - Manaus / AM. Como resultado de esta investigación, este artículo

1 Universidade Federal do Amazonas (UFAM), Manaus - AM - Brasil. Professora no Departamento de Administração e Planejamento e no Programa de Pós-Graduação em Educação. Doutorado em Educação (UFAM). ORICD: https://orcid.org/0000-0001-7629-7056. E-mail: heloborges@ufam.edu.br

${ }^{2}$ Universidade Federal do Amazonas (UFAM), Manaus - AM - Brasil. Professor Colaborador do Programa de Pós-Graduação em Ciências do Ambientes e Sustentabilidade na Amazônia. Doutorado em Sociedade e Cultura na Amazônia (UFAM). Tem bolsa pelo Tribunal de Contas no Projeto que pesquisa sobre patrimônio amazônico. ORCID: https://orcid.org/0000-0003-1529-7209. E-mail: casilva@ufam.edu.br

${ }^{3}$ Universidade Federal do Amazonas (UFAM), Manaus - AM - Brasil. Mestrado pelo Programa de PósGraduação em Educação. ORCID: https://orcid.org/0000-0002-6032-8097. E-mail: riulmaventura@gmail.com 
recibió el título de Política de la Reserva de Desarrollo Sostenible (RDS) de Tupé, en Amazonas, y Educación en el Contexto Amazónico, ya que se refiere a uno de los objetivos especificos, que es examinar los documentos de creación de esta RDS y sus políticas públicas para la educación. Los procedimientos metodológicos se basaron en estudios bibliográficos de varios autores: Brandão (2013), Caldart (2015), Freire (2003), Gohn (2020), Silva (2017), Muller (2019), Pinto (2010), Borges (2015). También se analizaron los siguientes documentos: Constitución Federal de 1988; LDB $n^{\circ} 9.394$ / 96; Ley $N^{\circ} 3.173$, de 6 de junio de 1957; Decreto Ley No. 288, de 1967; Decreto 8.044 / 2005, de creación de RDS / SEMMA (04/11/2020); Plan de Manejo (2016). A lo largo del estudio se pudo constatar que, en esta $R D S$, existen tres formaciones: la no formal, la formal y la informal. Los datos obtenidos revelan que, a pesar de la conquista de leyes que abordan las politicas públicas que atienden a las comunidades ribereñas, en materia de educación formal, especialmente Educación Básica, la Comunidad São João do Tupé sigue siendo atendida únicamente por políticas paliativas.

PALABRAS CLAVE: Contexto amazónico. Políticas públicas. Educación no formal. Educación formal. Educación informal.

ABSTRACT: The article presentes part of there search carried out in the Master's Degree Program in Educationat UFAM, from 2017 to 2019, entitled Public Policies and Field Education in the Amazon Context: Studyat Tupé RDS, in the Community of São João Manaus/AM. As a result of thisre search, this article received this title: Tupe Sustainable Development Reserve (RDS) in Amazonas and Education in the Amazon Context, because it refers to one of the specific objectives, which isto examine the documents creating this RDS and its public policies for education. The methodological procedures were based on bibliographical studies by several authors: Brandão (2013), Caldart (2015), Freire (2003), Gohn (2020), Silva (2017), Muller (2019), Pinto (2010), Borges (2015). The following documents were also analyzed: Federal Constitution of 1988; LDB No. 9.394/96; Law No. 3.173 of June 6, 1957; Decree Law No. 288 of 1967; Decree 8.044/2005, creating the RDS/SEMMA (04/11/2020); Management Plan (2016). Throughout the study it was possible to verify that, in this RDS, there are three educations: the non-formal, the formal andthe informal. The data obtained revealed that, in spite of the conquest of legislation that deal swith public policies that attend the river side communities, regarding formal education, especially Basic Education, the Community of São João in Tupé is still attended only by palliative policies.

KEYWORDS: Amazonian contexto. Public policy. Non-formal education. Formal education. Informal education.

\section{Introdução}

O artigo apresenta uma parte do estudo que foi desenvolvido no Programa de PósGraduação em Educação, no Curso de Mestrado da Faculdade de Educação (FACED) da Universidade Federal do Amazonas (UFAM), na linha de pesquisa de Políticas Públicas e Desenvolvimento Regional.

RIAEE - Revista Ibero-Americana de Estudos em Educação, Araraquara, v. 16, n. esp. 2, p. 1253-1266, maio 2021. e-ISSN: 1982-5587 
A pesquisa, que foi financiada pela Fundação de Amparo à Pesquisa do Estado do Amazonas (FAPEAM), ocorreu na Comunidade de São João do Tupé e foi norteada pelo seguinte problema: As políticas públicas desenvolvidas na Reserva de Desenvolvimento Sustentável (RDS) do Tupé, na Comunidade de São João, dialogam com a concepção da Educação do Campo?

Como já foi dito, este artigo é um recorte da dissertação para tratar sobre as educações que foram detectadas durante a realização da pesquisa. Nesse sentido, trataremos somente do segundo objetivo, que é examinar os documentos de criação da RDS e suas políticas públicas.

A pesquisa foi realizada por meio de estudos bibliográficos de vários autores, entre os quais Brandão (2013), Caldart (2015), Freire (2003), Gohn (2020), Silva (2017), Muller (2019), Pinto (2010) e Borges (2014). Analisamos vários documentos, dos quais aqui utilizamos os seguintes: Constituição Federal de 1988; Lei de Diretrizes e Bases da Educação Nacional (LDB) n. ${ }^{\circ}$ 9.394/96; Lei n. ${ }^{\circ}$ 3.173, de 6 de junho de 1957; Decreto-Lei n. ${ }^{\circ}$ 288, de 1967; Decreto n. ${ }^{\circ}$ 8.044/2005, de criação da RDS/SEMMA (04/11/2020); Plano de Gestão (2016).

O artigo encontra-se dividido da seguinte forma: 1) Contexto amazônico da pesquisa; 2) As educações presentes no campo amazônico da Comunidade de São João do Tupé. Nesse item, optamos por desenvolver três subitens: Comunidade de São João do Tupé e a Educação Informal; Educação Não Formal na Comunidade de São João do Tupé; Política de Educação Formal na Comunidade de São João do Tupé. Por fim, as considerações finais sobre o estudo.

\section{Contexto amazônico da pesquisa}

O Amazonas é um estado que possui 62 municípios, com território de $1.571 .000 \mathrm{~km}^{2}$. Nesse espaço geográfico há uma diversidade marcada pelas belezas naturais de rios, fauna, flora e sujeitos amazônicos; estes incluem caboclos, ribeirinhos, indígenas, coletores, semeadores, assentados, meeiros etc. Entre todos os municípios, existe a cidade de Manaus, que é a capital do Estado do Amazonas, a qual possui uma população de 2.219.580 habitantes (IBGE, 2020), localizada em frente ao encontro das águas dos rios Negro e Solimões, que, após essa confluência, tornam-se o Rio Amazonas.

A cidade de Manaus sedia um polo industrial, denominado de Zona Franca de Manaus, detentor de várias fábricas montadoras de eletroeletrônicos, de duas rodas, de alimentos, o que configura o município como um grande centro comercial com vários 
serviços. A eclosão do polo ocorreu a partir da Lei n. ${ }^{0}$ 3.173, de 6 de junho de 1957, mas foi efetivamente viabilizado com o Decreto-Lei n. ${ }^{\circ}$ 288, de 1967.

Ao longo das décadas, houve o crescimento da população, uma vez que o município se tornou atrativo para milhares de pessoas na busca por trabalho, seja da própria região, seja dos outros municípios do estado, do País, como também de outros países, em função da demanda por mão de obra pelas empresas multinacionais. O município possui um extenso espaço geográfico de $11.401 .092 \mathrm{~km}^{2}$, em que se insere uma variedade de espécies naturais. Nesse contexto, a Secretaria Municipal de Meio Ambiente (SEMMAS), em 2005, criou a única Reserva de Desenvolvimento Sustentável (RDS) do Tupé, a 15,5 km da área urbana do município de Manaus.

A RDS Tupé possui 11.973 hectares e foi criada pelo Decreto n. ${ }^{\circ} 8.044 / 2005$. Segundo o site da SEMMA (04/11/2020), ela abriga populações tradicionais que vivem da exploração sustentável dos recursos naturais, e tal criação da área tem como objetivo preservar o meio ambiente conforme as condições ecológicas locais. Tem ainda por finalidade o desenvolvimento e a implantação de projetos sustentáveis nas comunidades de Julião, Livramento, Agrovila, Central e São João do Tupé.

O território geográfico onde se encontra o Tupé já foi habitado por índios da etnia Barés, e, segundo Silva (2017), é uma região em que foram encontrados vários fragmentos de peças de sítios arqueológicos, cacos de louças de barro etc. Ainda conforme o pesquisador, os Barés localizam-se atualmente no Baixo Rio Negro, enquanto os Manaós e os Tarumã foram praticamente extintos da região.

A pesquisa ocorreu na comunidade de São João do Tupé, situada na margem esquerda do Rio Negro e do Lago Tupé, sendo limitada por praia, mata de igapó e terra firme (SILVA, 2017). Suas residências estão à beira do lago ou agrupadas na pequena vila que se estruturou nas proximidades da praia, e a ocupação demográfica da área vem ocorrendo ao longo de aproximadamente 40 anos.

Segundo o Plano de Gestão (2016), as famílias são originadas de migrantes, principalmente da Região Nordeste do Brasil, ou de grupos indígenas da região do Médio e Alto Rio Negro (dos municípios de Santa Isabel e São Gabriel da Cachoeira). As famílias estão organizadas de forma nuclear, e a média de pessoas que predomina por casa é de 3,9 pessoas.

A comunidade possui uma organização social por meio da Associação de Moradores, que atua com uma proposta de conscientizar sobre a importância da reserva para os que vivem lá, de combater os invasores que vêm da cidade de Manaus e estimular o aproveitamento 
sustentável da área na busca de alternativas para a geração de renda. Apesar do fato de a Comunidade de São João do Tupé ser uma área de preservação, é perceptível a ausência de políticas públicas que atendam às demandas das populações rurais que lá se encontram, como indígenas, pescadores e migrantes vindos de outras partes do país (MULLER, 2019).

Observou-se que os sujeitos estão na Reserva de Desenvolvimento Sustentável do Tupé mesmo antes da reformulação da RDS. Porém, eles são considerados um problema quando se fala sobre o desenvolvimento da Amazônia e a integração nacional, pois são tidos como atrasados e inferiores diante do modelo de sociedade capitalista que predomina no projeto da economia globalizada.

\section{As educações presentes no campo amazônico da comunidade de São João do Tupé}

Quando a pesquisa teve início, foi possível observar que na comunidade de São João do Tupé existia nas conversas informais a presença de duas consciências: a ingênua e a crítica, conceituadas por Álvaro Pinto (2010). Para o autor, a consciência ingênua está presente em muitas pessoas e independe da classe social a que pertencem, pois ela é atribuída àquela pessoa que não faz a leitura de mundo, como diz Paulo Freire (2019). Ou seja, não consegue fazer ligação entre a sua realidade e questões mais gerais que acontecem na sociedade, nos aspectos sociais, econômicos, políticos etc., os quais interferem em vários aspectos da vida, inclusive no âmbito cultural. O autor afirma que geralmente as situações vivenciadas pelas pessoas são tidas como naturais e normais, pois seus familiares anteriores também viveram circunstâncias semelhantes.

Nesse sentido, em decorrência das próprias conjunturas vividas pelos comunitários, foi notório e até natural que tenham a consciência ingênua como uma forma de explicar o mundo. Segundo o Plano de Gestão (2016. p 116), a “maioria dos moradores compartilha um histórico de vida que tem como traço comum associado ao fato de terem sido trabalhadores rurais nos ciclos econômicos do extrativismo na região".

Na comunidade de São João do Tupé vivem 275 pessoas em 95 famílias (PLANO DE GESTÃO, 2016). Nesse universo, encontram-se pessoas que possuem consciência crítica, conforme citado por Pinto (2003), que ocorre quando a pessoa detém uma representação mental do mundo exterior associada ao seu cotidiano e consegue compreendê-lo em sua totalidade, entendendo as contradições presentes ao seu redor de forma histórica. Assim, Pinto (2003) diz que a pessoa adquire consciência crítica quando ela se transforma e, 
consequentemente, passa a ter autoconsciência de si e percebe que as representações ao seu redor fazem parte do mundo a que pertence.

O momento em que é possível constatar a consciência crítica se dá quando o próprio Plano de Gestão (2016) faz as entrevistas com os comunitários, e eles apresentam as suas reivindicações por meio da organização deles, que é a Associação de Moradores, e passam a lutar por seus direitos junto à Secretaria Municipal de Meio Ambiente de Manaus, por estarem numa RDS e por terem seus direitos assegurados.

Assim, podemos dizer que as duas consciências citadas por Pinto (2003) existem na comunidade de São João do Tupé. Mas, além disso, constatou-se que existem três tipos de educações, às quais Carlos Brandão faz menção em seus estudos, que são a Educação Informal; a Educação Formal; a Educação Não Formal.

\section{Comunidade de São João Tupé e a Educação Informal}

A Educação Informal, segundo Brandão (2013), abarca um conjunto de conhecimentos desde a sua infância (linguagem) até a sua fase adulta (trabalho), pois o ser humano ao longo de sua vida vai vivenciando conhecimentos por meio da prática social, dado que, sendo criança, sendo adulto, é sempre um aprendiz de valores, de princípios, de saberes, que são muitas vezes resultados de sua própria experiência pessoal e de sua interação com o meio, ou seja, o ser humano recebe formação permanentemente, o que antecede a chegada do ensino institucionalizado.

Esse fato foi bem presente no período de observação que antecedeu a pesquisa, visto que os comunitários são pessoas que vivem há muito tempo na RDS e que possuem sua cultura, seus ensinamentos, seus saberes com base nas suas vivências, que são repassadas como orientações para as novas gerações.

Nesse sentido, segundo Pinto (2003) e Brandão (2013), a criança, o adulto, ou melhor, as pessoas vão à escola já preparadas pela própria sociedade e pelo meio onde vivem. Portanto, podemos dizer que a Educação não se dá somente a partir das instituições formais como a escola, mas também mediante a interação das pessoas com a sociedade em que vivem; elas trabalham, relacionam-se com os outros e com seu meio; e, nesse processo, há aprendizado, que serve como base de sua formação social. Ou seja, "ninguém escapa da educação" (BRANDÃO, 2013. p. 7) na família, na casa, na rua, na igreja ou mesmo na escola, de modo que o processo de aprendizagem se torna contínuo ao longo da vida. 
Dessa forma, podemos reconhecer que a educação existe de diversas formas e em diversos lugares por meio dos incontáveis processos educativos, desenvolvendo a pessoa e a sociedade como um todo, e não somente em lugares específicos como as instituições de ensino.

A educação não deve ser vista como uma transmissão de conhecimento, pois pensar dessa forma configura uma atitude ingênua na qual os professores são considerados simplesmente transmissores de conhecimentos acabados, que não se modificam ao longo do tempo e lugar em que estão inseridos. Porém, sabemos que os conhecimentos são dinâmicos e alterados segundo as relações do mundo exterior com seus sujeitos.

Os autores comungam da concepção da existência de educações, que ocorrem em diferentes ambientes e no cotidiano da vida dos indivíduos, além da ideia de que não existe uma única forma, e sim várias formas, afinal o conhecimento não é absoluto. Por isso, os comunitários estão na busca de melhorar as suas condições de vida por meio do rompimento talvez não tão profundo com a consciência ingênua, porque, mantendo as suas origens e seus saberes no decorrer da educação informal da comunidade, certamente essa ingenuidade dificultará a conquista de melhorias.

Diante da sua realidade, os comunitários dão passos rumo à consciência crítica quando procuram se organizar na Associação de Moradores da RDS do Tupé. Essa postura ratifica o que Pinto (2003) e Brandão (2013) afirmam, acerca do fato de que a escola não é o único lugar da educação, pois ela não é a exclusiva forma do conhecimento, e sim existem diversos locais em que ocorrem os processos formativos, em pequenos grupos ou grandes, como numa comunidade de caçadores, agricultores, boias-frias, assentados, ribeirinhos, indígenas, camponeses, quer em áreas urbanas, quer no campo.

Nesse caso, a educação se dá em diferentes mundos, culturas e povos, que a utilizam até como ferramenta para dominar outros povos; da família à comunidade, existe uma difusão entre os mundos sociais e as inúmeras práticas de aprendizado. A educação existe primeiramente sem classes de estudantes, sem livros didáticos e sem professores; e somente depois, formalmente, sobretudo as crianças irão para as escolas para terem conhecimento formal com os professores, com os livros e com as práticas pedagógicas.

\section{Educação Não Formal na Comunidade de São João do Tupé}

A educação não formal diz respeito a um conjunto de ações educativas que ocorrem de forma espontânea fora da escola (não constam nos currículos escolares) e podem acontecer 
em diversos espaços, como ONGs, sindicatos, instituições religiosas, iniciativas particulares, associação de moradores, cooperativas, entre outros. Nesse tipo de educação há projetos que utilizam o esporte, a arte ou a cultura como ferramentas do aprendizado.

Quando os sujeitos se tornam conscientes de seu papel social e passam a se organizar e se mobilizar em busca da transformação da ordem social existente mediante novos deveres e direitos humanos, e quando essa realidade é compreendida pelos sujeitos sociais, para Freire (2003, p. 80), significa que a "participação na realidade social mediante o trabalho proporciona os fundamentos para a participação política". Isso envolve atuação na sociedade de forma mais participativa, mas para isso é necessário que se tenha consciência de seu dever social para agir no meio ao qual pertence, por meio das organizações sociais.

Para compreender o papel da Educação Não Formal é importante que as pessoas se abram para realidade que vivem e não se coloquem na condição de submissão a ela. Pois, segundo Agostini e Silva (2019), a educação proporciona a relação com o mundo como sujeitos sociais, não como mero expectadores; sujeitos que procuram alterar a própria realidade e, com isso, também se modificam, numa inserção crítica.

Assim, os líderes de comunidades, associações, movimentos sociais e demais outros possuem papéis importantes no processo de desenvolvimento das lutas sociais para viabilização de políticas públicas na sociedade. É nesse sentido que os autores fazem referências à Educação Não Formal como um espaço de formação por meio das lutas reivindicatórias para viabilizar os direitos sociais, muitas vezes já assegurados em leis.

A Comunidade de São João do Tupé possui muitas dificuldades em relação às políticas públicas, visto que falta saneamento público, posto de saúde, transporte público etc. Seus moradores são considerados pelo Plano de Gestão (2016) como de baixa renda. As principais atividades de trabalho estão na pequena agricultura, na pesca, no turismo e no comércio.

Diante das condições em que os comunitários vivem, fica notório o porquê da criação da Associação de Moradores e dos envolvimentos com grupos religiosos, institutos de pesquisa, universidades, ONGs etc., por meio de cursos de extensões, em que eles passaram a fazer atividades formativas para melhorarem suas condições, geralmente ocorrendo a Educação Não Formal, uma vez que ela cria um processo com várias dimensões, as quais abrangem, segundo Gohn (2006. p. 28):

[...] a aprendizagem política dos direitos dos indivíduos enquanto cidadãos; a capacitação dos indivíduos para o trabalho, por meio da aprendizagem de habilidades e/ ou desenvolvimento de potencialidades; a aprendizagem e

RIAEE - Revista Ibero-Americana de Estudos em Educação, Araraquara, v. 16, n. esp. 2, p. 1253-1266, maio 2021. e-ISSN: 1982-5587 
exercício de práticas que capacitam os indivíduos a se organizarem com objetivos comunitários, voltadas para a solução de problemas coletivos cotidianos; a aprendizagem de conteúdos que possibilitem aos indivíduos fazerem uma leitura do mundo do ponto de vista de compreensão do que se passa ao seu redor; a educação desenvolvida na mídia e pela mídia, em especial a eletrônica etc.

A autora, quando cita os exemplos de Educação Não Formal, esclarece que são ações formativas ligadas ao meio social em que as pessoas estão envolvidas, com o intuito de fazer que ocorra a participação dos comunitários na resolução de seus problemas e que consigam romper com a consciência ingênua, tornando-se autônomos de suas vidas. Acrescenta ainda que é possível encontrar alguns pesquisadores que confundem a Educação Não Formal com a Educação Formal.

Por isso, é importante distinguir as duas educações. A Educação Não Formal é aquela que ocorre durante o processo formativo, que envolve aprendizagem rompendo com o modelo de mundo estabelecido pelas classes dominantes. Ela proporciona a compreensão da possibilidade de um novo paradigma para uma nova realidade social. Já a Educação Formal se dá nos ambientes escolares, acadêmicos, ou seja, em instituições regularmente apropriadas para o ensino e a aprendizagem, e seus currículos são definidos e aprovados pelos órgãos legais. Na prática, a escola é principal espaço que podemos denominar da Educação Formal, onde está concretamente o processo de transmissão e assimilação do conhecimento elaborado instrumentalmente para permanência da cultura existente (LEITE; CARVALHO, 2019. p. 1902).

\section{Política da Educação Formal na Comunidade de São João do Tupé}

Para Gohn (2016), a Educação Formal é aquela que se encontra em território conhecido por escolas, que são instituições regidas por lei, certificadoras, com base nas leis gerais do país, dos estados e dos municípios.

Para Pinto (2003), Brandão (2013) e Gohn (2016), a Educação Formal representa a presença do Estado como política de educação que vai da Educação Básica ao ensino superior, à pós-graduação etc. Ou seja, ela é aquela assegurada pela Constituição Federal no Art. 205: "A educação, direito de todos e dever do Estado e da família, será promovida e incentivada com a colaboração da sociedade, visando ao pleno desenvolvimento da pessoa, seu preparo para o exercício da cidadania e sua qualificação para o trabalho".

Mas, apesar do processo formal da educação, ainda deparamos com população sem escolaridade. No caso da Comunidade de São João do Tupé, segundo o Plano de Gestão 
(2016), em sua maioria, os moradores não possuem o ensino médio. Existe na comunidade, desde 2008, uma escola da Secretaria Municipal de Manaus (SEMED), com ensino do $6 .^{\circ}$ ao 9. ${ }^{\circ}$ ano "itinerante", em que o ensino é realizado por módulos concentrados de disciplinas em períodos de três meses. No ano de 2012, a Secretaria Estadual de Educação (SEDUC-AM) implantou escolas para atender do $1 .^{\circ}$ ao $3 .^{\circ}$ ano do ensino médio, de forma "itinerante", usando a modalidade do ensino a distância.

O que foi possível de constatar é que existe a Educação Formal na Comunidade como forma de atender aos direitos que estão assegurados na Constituição Federal e na própria Lei de Diretrizes e Bases da Educação Nacional (LDB), n. ${ }^{\circ}$ 9.394/96, e que ela acaba compensando a educação defasada que os pais das crianças que frequentam os bancos escolares tiveram em seu processo formativo.

Isso é notório de perceber no trecho do Plano de Gestão (2016. p. 123):

Os pais apresentam baixa escolaridade, o que na prática lhes impossibilita de oferecer uma orientação mais sistemática aos filhos no tocante ao desenvolvimento das tarefas escolares, visto que não adquiriram conhecimentos formais que lhes favorecem uma prática orientacional mais incisiva aos filhos, o que hoje é considerado de extrema importância para o bom desempenho escolar das crianças.

Então, a Educação Formal com que a escola proporciona a instrução dos processos de ensino e aprendizagem por si só já apresenta procedimentos metodológicos que não consideramos regulares pelo fato de o ensino dos conteúdos curriculares ser itinerante e sem fazer ligação com a vida das famílias da comunidade. Segundo o Plano de Gestão (2016), os pais dos estudantes não possuem escolaridade suficiente para orientar seus filhos nos conteúdos escolares.

Mas existem outros obstáculos em relação à Educação Formal (escolar). Um deles é a distância geográfica de $15,5 \mathrm{~km}$ da comunidade ao centro da cidade de Manaus, o que dificulta diariamente a ida e a vinda dos professores a partir da comunidade, pois eles dependem de transporte fluvial, que não é regular nem pontual. Muitas vezes há também a falta de combustível para o deslocamento, o que impossibilita o funcionamento constante das atividades formativas da escola, prejudicando ainda mais o rendimento escolar dos estudantes.

É bem verdade que existe o calendário diferencial das escolas do campo, adaptado cronologicamente aos dias letivos, em função das questões climáticas de seca do Rio Negro e do Rio Tarumã-Mirim. Mas o translado não é só o fluvial: há também o terrestre, pois os estudantes precisam caminhar cerca de $5 \mathrm{~km}$ de suas residências à escola. 
A Educação Formal (escolar) é mantida pela Secretaria de Educação, que viabiliza os pagamentos dos salários dos professores, condutores fluviais, merendeiras e vigias, transportes para os professores e estudantes, material didático, merenda escolar, combustível para o funcionamento do gerador de energia e pagamento de conta de energia elétrica.

Todas essas questões evidenciam a presença de políticas públicas, apesar das dificuldades presentes na comunidade, observadas durante as visitas à área e nos documentos estudados. Ou seja, mesmo que a educação seja "um direito humano fundamental e um dos principais meios de acesso à cultura, além de um instrumento poderoso de desenvolvimento econômico e social" (CARDOSO NETO; DE NEZ, 2020 p. 806), ela não atende devidamente os comunitários.

Diante dessas circunstâncias, podemos citar Caldart (2020. p. 74), quando ela faz referência à necessidade de que a escola do campo seja diferente das escolas urbanas, pela dificuldade presente nas comunidades, como constatamos na Comunidade de São João do Tupé, haja vista que "o campo não é qualquer particularidade; [...] ele diz respeito a uma boa população do País; se refere a processos produtivos que são a base de sustentação da vida humana", de forma que se garanta a viabilidade da construção de "[...] políticas públicas, a escola, os processos formativos, entre outros [...] visando que os sujeitos do campo alcancem emancipação humana e transformação social” (CALDART, 2020, p. 75).

Nessa mesma direção, Borges (2015) comunga que a Educação do Campo é uma concepção que surge como uma reivindicação dos sujeitos do campo, ou seja, a partir da tomada de consciência crítica, os sujeitos do campo e seus movimentos sociais, com o apoio das universidades públicas, passaram a lutar para assegurar as políticas específicas para a escola do campo, sobretudo as Diretrizes Nacionais para Escolas da Educação Básica do Campo. Dessa forma, a Educação do Campo visa a uma formação integral da pessoa do campo em todo o contexto social, político, econômico e cultural, relacionando sua vida e seu trabalho rumo à perspectiva de transformação social e de emancipação humana.

\section{Considerações Finais}

Verificamos que existem diversas formas de educação na Comunidade de São João do Tupé. No primeiro momento averiguamos a Educação Informal, presente no cotidiano das pessoas da comunidade e que é natural por advir das experiências pessoais, sociais, culturais, econômicas, religiosas e políticas que os moradores desenvolvem na sociedade em que estão inseridos. 
A Educação Não Formal está relacionada às organizações sociais existentes na comunidade, que fazem o diálogo com o poder público para garantir o atendimento das Políticas Públicas. Concluímos que ela é de suma importância na vida das pessoas do campo, já que faz parte de toda ação educativa que ocorre fora do espaço escolar (escola) e que está totalmente relacionada com a vida em sociedade, como associações de moradores, movimentos sociais, instituições religiosas, entre outras.

Já a Educação Formal é a instituída pelas legislações para atender à população, a qual, entretanto, nem sempre corresponde às expectativas no sentido da qualidade do atendimento da comunidade. Essa modalidade é fundamental na vida dos educandos que vivem e trabalham na Comunidade, porém deve proporcionar que a construção de saberes desenvolvidos em seu interior não fique deixada às quatro paredes de sua instituição formal de ensino, mas sim que transponha esse limite e atinja as famílias, outras instituições e outros sujeitos civis na construção de uma melhor qualidade de vida para todos.

Portanto, concluímos que a Política da Reserva de Desenvolvimento Sustentável (RDS) do Tupé, no Amazonas, e as Educações no Contexto Amazônico estão presentes na comunidade, assim como os três tipos de educação: a informal, a não formal e a formal, tríade do processo em que se proporciona a superação da consciência ingênua para a consciência crítica, na busca da melhoria de vida dos moradores.

\section{REFERÊNCIAS}

AGOSTINI, N.; SILVA, L. B. O. Educação e Formação Crítica na Atualidade. RIAEE Revista Ibero-Americana de Estudos em Educação, Araraquara, v. 14, n. esp. 4, p. 1977 1992, dez. 2019. E-ISSN: 1982-5587. DOI: https://doi.org/10.21723/riaee.v14iesp.4.12922

BORGES, H. S. A política e aspectos legais na formação da educação brasileira. In: BORGES, H. S.; JÚNIOR, W. M. V. (Org.). Educação do Campo e as Políticas Sociais Públicas. Boa Vista: Editora da UFRR, 2015.

BRANDÃO, C. R. O que é Educação. São Paulo: Brasiliense, 2013. (Coleção Primeiros Passos)

BRASIL. Constituição (1988). Constituição da República Federativa do Brasil. Brasília, DF: Senado, 1988.

BRASIL. Decreto-Lei n. 288, de 28 de fevereiro de 1967. Altera as disposições da Lei número 3.173 de 6 de junho de 1957 e regula a Zona Franca de Manaus. Diário Oficial da União: Seção 1, Brasília, DF, p. 2464, 28 fev. 1967. 
BRASIL. Lei n. 3.173, de 6 de junho de 1957. Cria uma zona franca na cidade de Manaus, capital do Estado do Amazonas, e dá outras providências. Diário Oficial da União: Seção 1, Brasília, DF, p. 15285, 12 jun. 1957. PL 1310/1951

BRASIL. Lei n. 9.394, de 20 de dezembro de 1996. Lei de Diretrizes e Bases da Educação Nacional. Diário Oficial da União: Seção 1, Brasília, DF, n. 248, p. 27833, 23 dez. 1996. PL $1258 / 1988$

CALDART, R. S. Caminhos para transformação da escola. São Paulo. Editora Expressão Popular, 2015. v. 2.

CARDOSO NETO, O. F.; DE NEZ, E. Plano Municipal de Educação (PME): Valorização e Desafios da Carreira Docente. RIAEE - Revista Ibero-Americana de Estudos em Educação, Araraquara, v. 15, n. esp. 1, p. 796-809, maio 2020. e-ISSN: 1982-5587. DOI: https://doi.org/10.21723/riaee.v15iesp.1.13350

FREIRE, P. Pedagogia da autonomia: saberes necessários à prática educativa. São Paulo. Editora Paz \& Terra, 2019.

GOHN, M. G. Educação não formal e cultura política. São Paulo. Editora Cortez, 2020.

LEITE, S. R. M.; CARVALHO, A. B. Indústria Cultural, Currículo e Formação de Professores: A dimensão Ética como articuladora no Processo Pedagógico. RIAEE - Revista Ibero-Americana de Estudos em Educação, Araraquara, v. 14, n. esp. 4, p. 1899-1912, dez. 2019. E-ISSN: 1982-5587. DOI: https://doi.org/10.21723/riaee.v14iesp.4.12913

MANAUS. Decreto n. 8.044/2005, de criação da RDS/SEMMA. 2005.

MULlHeR, R V. Políticas Públicas na RDS do Tupé: um estudo com base na concepção da educação do campo. Manaus. PPGE/UFAM, 2019.

PINTO, Á. V. Sete lições sobre a educação de adultos. 13. ed. São Paulo: Cortez, 2010. PLANO DE GESTÃO RDS do Tupé. SEMMA. Manaus, 2016.

SILVA, C. A. A História das sociedades humanas: interação na área da zona leste de Manaus, Brasil, antes da viagem de Francisco de Orellana. Revista contracorrente, v. 9, 2017. 


\section{Como referenciar este artigo}

BORGES, H. S.; SILVA, C. A.; MULLER, R. V. Política da Reserva de Desenvolvimento Sustentável (RDS) do Tupé, no Amazonas, e as educações no contexto Amazônico. Revista Ibero-Americana de Estudos em Educação, v. 16, n. esp. 2, p. 1253-1266, maio 2021. eISSN: 1982-5587. DOI: https://doi.org/10.21723/riaee.v16iesp2.15124

Submissão em: $15 / 12 / 2020$

Revisões requeridas em: 28/01/2021

Aprovado em: 03/03/2021

Publicado em: 01/05/2021 